\title{
Etapas da implementação da educação corporativa e seus impactos em empresas brasileiras: um estudo multicaso
}

\author{
Fábio Henrique Antunes Vieira ${ }^{\mathrm{a}}$, Antonio Carlos de Francisco ${ }^{\mathrm{b} *}$ \\ acurso_structural@hotmail.com, FAIT/FATEC, Brasil \\ b*acfrancisco@utfpr.edu.br, UTFPR, Brasil
}

\begin{abstract}
Resumo
Este trabalho apresenta a Educação Corporativa - EC nas organizações brasileiras, como uma forma de aprendizado contínuo, apesar dessa prática ainda estar em fase de amadurecimento no País. 0 objetivo da pesquisa é avaliar as etapas da implementação do processo da EC através de um estudo multicaso. Foi observado que a implementação da unidade de EC deve levar em consideração a singularidade de cada empresa, com suas características e especificidades. Pode-se concluir que a maioria das empresas desse estudo indicou que a implementação foi realizada após decisão dos dirigentes como a etapa inicial. Mesmo inexistindo uma fórmula capaz de atender às especificações das mais diversas organizações, houve uma sequência lógica para a estruturação e implementação da unidade.
\end{abstract}

Palavras-chave

Educação corporativa. Aprendizado contínuo. Organizações brasileiras.

\section{Introdução}

O constante desenvolvimento dos processos e técnicas que chegam até as organizações também atingiu o setor de aprendizagem. Os antigos departamentos de Treinamento e Desenvolvimento têm se tornado cada vez mais obsoletos, aparecendo um sistema mais completo de aquisição de conhecimentos - a Educação Corporativa (EC).

No começo eles eram como centros de melhoria de competências técnicas. Esta situação permaneceu até a década de 1980, quando empresas de alta tecnologia, com investimentos significativos em matéria de investigação e desenvolvimento, começaram um novo ciclo de desenvolvimento para as unidades de EC (TARAPANOFF, 2004).

Durante este período, as organizações testemunharam uma redução da validade de seu conhecimento e começaram a perceber que já não era possivel confiar em Instituições de Ensino Superior para desenvolver a sua mão de obra. Foi necessário conectar os programas de aprendizado com os objetivos estratégicos e resultados das organizações.
Entre as principais características das empresas modernas está a estrutura horizontal e mais flexível, com descentralização das tomadas de decisão. 0 resultado está direcionado para o desenvolvimento das capacidades individuais numa base contínua, para que as empresas possam manter útil e eficiente seu capital intelectual. A rapidez na adoção de novas estratégias provocou o surgimento de um novo ambiente empresarial caracterizado por profundas e frequentes mudanças para garantir a sobrevivência da organização, e que gera, assim, um impacto significativo sobre os gestores que as empresas esperam formar e manter dentro das suas estruturas (EBOLl, 2004).

Eboli (2004) menciona também que, para poder confiar em trabalhadores com as competências essenciais para cada função, as organizações precisam construir sistemas educacionais que enfatizam o desenvolvimento não apenas dessas competências, mas das atitudes e da ética profissional. 
Este perfil dos colaboradores leva à criação de vantagem competitiva sustentável, ou seja, o compromisso da organização em manter o desenvolvimento contínuo de seus funcionários à obtenção de melhores resultados. Assim, a ideia de Educação Corporativa surgiu como uma ferramenta eficaz para o alinhamento e desenvolvimento de talentos humanos, de acordo com as estratégias organizacionais.

Por outro lado, observa-se que apenas grandes organizações têm aplicado os seus recursos financeiros sobre a área (BRASIL, 2007), principalmente devido à implementação e custos de manutenção. Além disso, o retorno sobre o investimento não é muito claro quando se trata de valores, e organizações têm encontrado dificuldades para realizar investimentos sem resultados concretos.

0 objetivo deste artigo é o de demonstrar o estado de desenvolvimento da pesquisa sobre Educação Corporativa nas organizações nacionais, especificamente o de apresentar e avaliar as etapas de implementação do processo de EC nas empresas em estudo.

\section{Educação corporativa}

O início da EC aconteceu no Instituto de Desenvolvimento de Gestão Jack Welch, na General Electric, em Nova lorque, em 1956. 0 objetivo da criação era o de melhor educar e formar seus gestores. Desde então, outras empresas começaram a utilizar um investimento maior na aquisição do conhecimento, criando as suas unidades de EC (MEISTER, 1998a).

De acordo com Meister (1999), a EC pode ser entendida como a união de práticas estruturadas por uma empresa com o propósito de promover a educação continuada, a melhoria da qualificação profissional, empresarial e de aprendizagem. Além disso, a EC pode ser definida como o ato de aprendizagem, permitindo que o colaborador assimile novas aquisições, novas competências e novas atitudes, incentivando seu crescimento, desenvolvimento e capacidade de adaptação às exigências do mercado.

As unidades de EC são desenvolvidas por empresas que mudaram seu enfoque de formação do colaborador para educação do colaborador, como resultado do aparecimento da economia do conhecimento.

A expressão "economia do conhecimento" demonstra que essas corporações reconheceram sua responsabilidade de proporcionar educação aos trabalhadores. Muitas empresas acreditam que, com a formação contínua dos trabalhadores ou a Educação Corporativa, podem atingir as metas estratégicas e melhorar seu desempenho (MEISTER, 1998b).
0 conceito de EC não se limita, necessariamente, ao âmbito de aplicação da empresa. Educação corporativa começa com a preparação dos trabalhadores de uma empresa, evoluindo para o serviço do público externo, fornecedores, clientes e franquias, além de desenvolver parcerias com faculdades e universidades. Neste sentido, ela não pode ser confundida com as instituições de ensino superior, porque não funciona com a amplitude de conhecimento e não concede diploma (ALPERSTEDT, 2001).

Como o processo de EC foi gerido por um longo período pelo Departamento de Recursos Humanos, não se pode afirmar que este departamento por si só será responsável pela formação das partes interessadas dentro e fora das organizações na atualidade. No ponto de vista das práticas da EC, há o envolvimento de todos na divulgação do conhecimento. 0 próprio termo "educação corporativa" tem sido utilizado para descrever as ações de formação e desenvolvimento de pessoal, seja em aulas presenciais ou ensino a distância. Isso ocorre provavelmente porque, ao contrário do passado, as organizações precisam aperfeiçoar seus funcionários em uma escala mais ampla. É imperativo ensinar os colaboradores de forma mais profunda e contínua, ajustando-se ao conceito da EC (VARGAS; LIMA, 2004).

De acordo com Allen (2002), a EC aparece como a alternativa mais abrangente entre as recentes tendências de formação e de desenvolvimento, através da adição de todas as ações educativas e de formação da organização, além de apresentar atividades que estão relacionadas com a gestão do conhecimento.

Meister (1998b) declara ainda que a EC é como uma fortaleza e um elemento representativo da Gestão Corporativa do Conhecimento para a criação e manutenção de vantagens competitivas, inspirada em uma formação permanente e um desempenho excepcional. 0 objetivo de qualquer programa de EC é o aumento das competências básicas do trabalho e do capital intelectual da empresa.

Dessa forma, a EC se baseia numa perspectiva mais ampla e seu desafio é o de criar uma nova cultura, na qual a educação é um processo inerente a toda forma de trabalho, em qualquer nível da organização. Para que a mudança cultural aconteça, é também necessária uma mudança de atitude das pessoas envolvidas no processo, e que seja entendida a verdadeira ligação entre a EC e as estratégias organizacionais.

Este ponto de vista é também compartilhado por Fleury e Fleury (2001), que ensinam que a educação corporativa é definida como um sistema de desenvolvimento de recursos humanos, orientada pelas competências de gestão, cujo principal papel é o de construir as competências empresariais e humanas consideradas críticas para a viabilidade da estratégia de uma organização. 
Uma diferença notória que é salientada pela EC refere-se aos ambientes de aprendizagem. Eles são pró-ativos, centralizados, determinados e estratégicos e os resultados esperados são de que o colaborador possa desenvolver a capacidade de aprender e de continuar este processo na volta ao trabalho. Tal como mencionado por Meister (1999), as empresas estão começando a compreender a necessidade de mudar o foco dos esforços da formação para a EC, uma vez que, essa última considera o ambiente corporativo como um todo e permite que a aprendizagem organizacional seja direcionada ao resultado macro e não só para a melhoria individual. Ela acrescenta valor aos resultados corporativos.

A missão da CE seria, então, proporcionar educação continuada e o compartilhamento de conhecimentos, de modo que todo o capital intelectual da organização tenha qualificações necessárias para manter vantagem competitiva.

Para Eboli (2004), o sistema da EC surge para aumentar a competitividade e o valor das empresas através do aumento do capital intelectual delas. A EC instala, desenvolve e consolida as competências essenciais através da Gestão do Conhecimento e Gestão de Pessoas por Competências. Por conseguinte, essa quantidade de atitudes à inteligência da empresa perpetua a mentalidade de aprendizagem contínua.

Comungando da mesma ideia, Blass (2005) afirma que a EC é uma estratégia que contribui para o alinhamento das competências, da aprendizagem, e de conhecimentos que vão ao encontro das necessidades da empresa e de seus colaboradores. A EC fornece customização e celeridade na entrega da aprendizagem; cria um ambiente de aprendizagem organizado; incentiva e prioriza o aprendizado como valor estratégico; disponibiliza o conhecimento para o desenvolvimento pessoal e profissional dos colaboradores; promove o crescimento e a retenção de talentos; além de unir as experiências do dia a dia com o conhecimento acadêmico, facilitando a execução das tarefas por parte dos funcionários.

No Brasil, algumas empresas já iniciaram suas unidades de educação corporativa há cerca de 20 anos, mas a maioria delas descobriu as vantagens de alinhar os processos educativos com as estratégias empresariais recentemente, segundo o MDIC/STI - Ministério do Desenvolvimento, Indústria e Comércio/Secretaria de Tecnologia Industrial (BRASIL, 2007).

Essa mesma secretaria salienta o aumento do número de empresas nacionais que adotaram unidades de EC dentro de seu ambiente de trabalho nos últimos anos, deduzindo assim, que essas unidades trazem vantagens para os interessados.

Por outro lado, Eboli (2004) aponta para os fatores críticos para a criação de uma unidade de
EC, ou seja, os obstáculos comumente encontrados nessa formação: a falta de compromisso da direção da empresa com o projeto; obscuridade em determinar qual será o público-alvo e a quantidade de produtos e serviços que serão oferecidos; má compreensão do âmbito de atuação da organização; escolha errônea de suas parcerias de ensino; mau desenvolvimento de ferramentas de medição; e o esquecimento da criação de uma estratégia de marketing e comunicação para a universidade.

Meister (2006) corrobora com essas ideias e acrescenta a falta de consenso entre os gerentes de nível médio sobre a necessidade de uma unidade de EC, além da incapacidade de desenvolver um elo entre a unidade e os objetivos estratégicos da empresa.

De acordo com Vianna (2004), um gargalo que as empresas encontram na formação da unidade de EC está na dissolução do departamento de T\&D em prol da criação de um novo departamento, normalmente chamado de Universidade Corporativa. A empresa não deve entrar em conflitos, pois forças em sentido contrário levam à perda do foco da empresa.

\section{Considerações metodológicas}

0 presente estudo incide sobre um aprofundamento teórico da EC no Brasil e um estudo multicaso nas organizações brasileiras. Os dados teóricos tentam interpretar e compreender a realidade. De acordo com os procedimentos técnicos (GlL, 1999), uma pesquisa bibliográfica foi feita devido ao levantamento de dados sobre sites, revistas, artigos, teses e livros pesquisados.

Com relação ao procedimento técnico, essa pesquisa será um estudo de caso, mais precisamente caracterizando um estudo multicaso. Um estudo de caso, por tratar de um fenômeno contemporâneo dentro de seu contexto real, no qual os limites entre o fenômeno e o contexto não estarem claramente percebidos (YIN, 2001).

Os dados empíricos apresentados neste trabalho foram preparados através de entrevistas e questionários com coordenadores das unidades de EC em 9 (nove) grandes organizações nacionais. 0 sistema utilizado para determinar o tamanho da empresa foi descrito pelo Sebrae - Serviço Brasileiro de Apoio às Micros e Pequenas Empresas (2007). As grandes empresas devem conter mais de 499 trabalhadores para a indústria e, pelo menos, 100 empregados de comércio e serviços.

Com relação à participação das organizações no mercado brasileiro, os gestores responsáveis por cada empresa informaram a situação de suas unidades econômicas de produção e distribuição de bens e serviços, conforme Quadro 1. Há empresas da área financeira, militar, da indústria, comércio, energia, telecomunicação e alimentos. 
Quadro 1. Perfil das empresas no mercado.

\begin{tabular}{|l|l|}
\hline \multicolumn{2}{|c|}{ Participação das organizações no mercado } \\
\hline Empresa "A" & $\begin{array}{l}\text { De acordo com os resultados de 2006, representou um faturamento perto de } 15 \% \text { do PIB nacional, somando todos os seus } \\
\text { associados. }\end{array}$ \\
\hline Empresa "B" & É líder nacional em vendas de seus produtos e detém aproximadamente 62\% do mercado interno em soluções de seus serviços. \\
\hline Empresa "C" & É líder do mercado interno e o segundo maior do setor no mercado mundial. \\
\hline Empresa "D" & É responsável pelo abastecimento de 62,5\% de seus serviços na região onde atua. \\
\hline Empresa "E" & $\begin{array}{l}\text { Além de atuar diretamente na proteção e segurança, também assiste populaços carentes e promove o desenvolvimento } \\
\text { tecnológico em diversas áreas. }\end{array}$ \\
\hline Empresa "F" & Detém 20,6\% do marketshare no País. \\
\hline Empresa "G" & É a maior empresa do setor no Brasil. \\
\hline Empresa "H" & É a segunda maior na sua área no Brasil e a 19a do mundo. \\
\hline Empresa "l" & É a maior exportadora nacional de seus bens. \\
\hline
\end{tabular}

Fonte: elaborado a partir dos dados das entrevistas.

A amostra foi obtida por acessibilidade, dentre 89 empresas listadas no site do Portal da Educação Corporativa do Ministério do Desenvolvimento, Indústria e Comércio, que descreve a prática da EC alinhada aos objetivos estratégicos dessas organizações.

As entrevistas foram realizadas de março a junho de 2008. Uma das organizações não concedeu entrevista, apesar de ter respondido o questionário. Os questionários foram respondidos por e-mail durante os meses de novembro de 2007 a março de 2008.

As questões do questionário foram desenvolvidas de maneira a obter não apenas dados quantitativos, mas que possam ser analisados e interpretados. Há questões de fato, de múltipla escolha e outras de avaliação, nas quais os respondentes atribuíram "valores" aos itens de acordo com sua importância.

0 critério de valores, "3" para maior importância, "0" para menor importância, "1" e "2" para posições intermediárias, foi utilizado a partir do modelo de pontuação do grau de importância de cada atividade em EC, usado inicialmente pelo Ministério do Desenvolvimento, Indústria e Comércio Exterior em 2004.

\section{Cenário da EC neste estudo}

Como parte das informações fornecidas nas entrevistas e questionários, o ano da implantação da unidade de EC, nomeada na maioria das vezes como Universidade Corporativa, foi informado pelos responsáveis como sendo entre 1997 e 2006, o que indica que ainda são setores recentes dentro das organizações.

De acordo com Eboli (2004), a Universidade Corporativa aparece no fim do século 20 como o setor de maior crescimento no ensino superior. Além disso, é o segmento de mais rápido crescimento do mercado da educação para adultos, de acordo com Meister (1998b). Essa última autora também afirma que o verdadeiro surto de interesse na criação de uma Universidade Corporativa, como complemento estratégico da gestão de T\&D dos funcionários das organizações, ocorreu no final da década de 80 no mundo todo.

\section{Etapas da implementação da EC}

Com relação à pergunta acerca da ordem das etapas de implementação do processo de EC, através do questionário, os respondentes ao questionário poderiam optar por 4 (quatro) fases distintas: Um projeto novo de implantação foi desenvolvido; Foi realizado um diagnóstico das competências críticas da empresa; Houve um estudo sobre a avaliação dos colaboradores nos treinamentos anteriormente desenvolvidos; ou A implantação foi realizada após decisão dos dirigentes.

A maioria, 66,6\% das respostas, indicou que a implantação foi realizada após decisão dos dirigentes como a etapa inicial para a criação de um projeto. A segunda etapa, de acordo com a maioria das respostas, 66,6\%, se deu através de um diagnóstico das competências críticas da empresa.

A terceira etapa foi um estudo sobre a avaliação dos colaboradores nos treinamentos anteriormente desenvolvidos $(44,4 \%)$. A quarta e última etapa foi a de que um novo projeto de implantação foi desenvolvido $(33,3 \%)$.

É constatado através desses dados que houve uma nova mentalidade sobre os programas educacionais nas organizações. As respostas indicam uma decisão hierárquica da criação de um projeto para a implantação da EC, passando pelo diagnóstico das competências críticas para a empresa e avaliação dos colaboradores nos treinamentos anteriores desenvolvidos, até atingir uma proposta inovadora de projeto para a implantação da EC (Figura 1).

Observam-se 5 etapas na Figura 1, porém deve-se realçar que a primeira, decisão dos dirigentes, levou à criação de um projeto inicial de implantação. A partir desse ponto, contaram-se as demais etapas. 


\begin{tabular}{|c|c|c|c|c|}
\hline $\begin{array}{c}\text { Decisão dos } \\
\text { dirigentes }\end{array}$ & $\begin{array}{c}\text { Projeto inicial } \\
\text { de implantação }\end{array}$ & $\begin{array}{c}\text { Diagnóstico das } \\
\text { competências }\end{array}$ & $\begin{array}{c}\text { Avaliação dos } \\
\text { treinamentos } \\
\text { anteriores }\end{array}$ & $\begin{array}{l}\text { Novo projeto de } \\
\text { implementação }\end{array}$ \\
\hline
\end{tabular}

Figura 1. As etapas do processo de implementação da EC em uma organização. Fonte: Elaborado a partir dos dados dos questionários e entrevistas.

Assim, a decisão de iniciar uma unidade da EC parte dos responsáveis pela estratégia da organização, que consideram essa prática da gestão do conhecimento essencial para o aprimoramento de seu capital intelectual.

Na sequência, o projeto é montado para que haja, na maioria das empresas pesquisadas, uma transição tranquila do departamento de T\&D para essa nova estrutura do aprendizado.

A seguir, faz-se um diagnóstico das competências existentes e daquelas desejadas para os colaboradores. Essas competências são baseadas nos interesses essenciais de cada organização, além do próprio aprimoramento dos indivíduos.

Para se analisar o que é preciso alcançar com a EC, busca-se o alinhamento das estratégias da empresa com as competências necessárias. Já para a análise das competências existentes, os resultados das avaliações dos treinamentos previamente realizados são acessados nos bancos de dados das organizações.

Esses resultados apontam os pontos fortes e as oportunidades de melhoria nas competências dos colaboradores, constituindo a quarta etapa sugerida por essa pesquisa.

Só então, acontece a última etapa, que é um novo projeto de implementação, no qual as decisões de direcionamento das ações são tomadas, levando-se em conta a estratégia de cada organização. Essa etapa é caracterizada pela customização das ações, visto que, são as próprias empresas que escolhem as metas para o período, por terem missões específicas.

Todavia, as etapas do processo de implantação da EC em uma organização, elaboradas por Bohlander, Snell e Sherman (2003), demonstram outra sequência, conforme Figura 2.

Essas opções descritas na Figura 2 também fizeram parte do questionário-piloto para essa pesquisa. Porém, não se mostraram tão eficazes para identificar as etapas de implementação do processo em EC, sendo trocadas pelas alternativas do questionário atual.

Pode-se inferir dessas informações que houve um novo modo de pensar sobre os programas educacionais nas organizações. As respostas indicam uma decisão hierárquica e proposta inovadora de um projeto para a implantação da EC.

Além desses dados obtidos através do questionário, houve uma confirmação das respostas na entrevista.

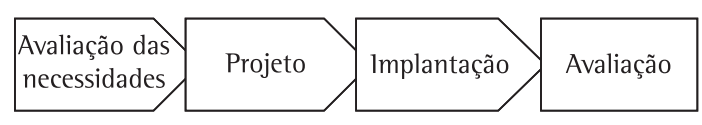

Figura 2. As etapas do processo de implantação da EC em uma organização. Fonte: Elaborado a partir de BOHLANDER, G.; SNELL, S.; SHERMAN, A. Administração de Recursos Humanos. São Paulo: Pioneira Thomson Learning, 2003.

Como os coordenadores das unidades de EC tiveram liberdade para responder, houve diferentes etapas de implantação do processo de EC, mas destacaram-se: Benchmarking, Levantamento da demanda, Capacitação dos gestores responsáveis pela implantação e Atualização dos modelos de ensino.

\section{Ações e motivos que favoreceram a efetivação da EC}

Nessa fase do questionário, foi indagado quanto às ações que favoreceram a efetivação das atividades em EC na organização. Os responsáveis pela unidade de EC na empresa puderam escolher o grau de importância de uma sequência de ações listadas.

Todas as 9 (nove) empresas responderam a esta pergunta, atribuindo " 3 " para o mais importante, "2" para importância intermediária, "1" para menor importância e "0" para as ações não consideradas. Nota-se que havia uma opção aberta de resposta, com o título de "outra", na qual o coordenador da unidade de EC poderia descrever atividades não previstas no questionário. Não houve, porém, resposta diferente das do questionário, para essa pergunta.

Os dados foram apurados e obteve-se a média das respostas de todas as organizações. Então, através do resultado, foi feita uma divisão das ações mais importantes, de média importância e de pouca importância no favorecimento da efetivação das atividades em EC.

Na Tabela 1, observam-se as ações de maior importância, de acordo com os responsáveis pela EC na organização. Destaca-se o envolvimento de líderes e gestores da empresa com o processo de aprendizagem contínua, com média de 2,78 pontos.

Esta resposta, indicada como de maior importância pelas organizações deste estudo, está em comunhão com Meister (1999), quando a autora se refere a 
Tabela 1. Ações consideradas de maior importância no favorecimento da efetivação da EC.

\begin{tabular}{lc}
\hline \multicolumn{1}{l}{ Atividades que mais favoreceram a implantação da EC } & Pontos \\
\hline $\begin{array}{l}\text { Envolver líderes e gestores da empresa com o processo de } \\
\text { aprendizagem contínua }\end{array}$ & 2,78 \\
$\begin{array}{l}\text { Favorecer a mudança da cultura organizacional } \\
\text { Criar um ambiente organizacional favorável à aprendizagem }\end{array}$ & 2,67 \\
$\begin{array}{l}\text { contínua } \\
\text { Favorecer o cumprimento dos objetivos estratégicos da }\end{array}$ & 2,44 \\
empresa & 2,44 \\
$\begin{array}{l}\text { Melhorar as competências essenciais para a empresa } \\
\text { Utilizar novas tecnologias para a disseminação do } \\
\text { conhecimento }\end{array}$ & 2,22 \\
$\begin{array}{l}\text { Aumentar oportunidades de melhoria de competências } \\
\text { nas áreas técnicas }\end{array}$ & 2,22 \\
\hline $\begin{array}{l}\text { Fonte: Elaborada a partir dos dados dos questionários e entrevistas. } \\
\end{array}$
\end{tabular}

um dos princípios da EC, "Encorajar e facilitar o envolvimento dos líderes com o aprendizado inclusive como facilitadores."

Já nos departamentos de T\&D tradicionais há uma preferência pela contratação de instrutores externos toda vez que é constatada uma necessidade de treinamento. Normalmente empresas de consultorias enviam seus professores, os quais apresentam pouca interação com a realidade da organização e, às vezes, até com o ramo do negócio. Entretanto, as unidades de EC procuram dar oportunidades para seus gestores internos, estimulando-os à liderança e à participação direta no processo de aprendizagem (FERNANDEZ, 2005).

Em seguida, aparece o favorecimento à mudança da cultura organizacional, com média de 2,67. Empatadas com 2,44 pontos, vêm as ações de "Criação de um ambiente organizacional favorável à aprendizagem contínua", o "Favorecimento do cumprimento dos objetivos estratégicos da empresa" e o "Melhoramento das competências essenciais para a empresa".

Com relação à última ação descrita, "Melhorar as competências essenciais para a empresa", Dalmau (2003) salienta que as empresas estão cada vez mais preocupadas em se manter no mercado de maneira competitiva e são obrigadas, para tanto, a criar mecanismos capazes de alavancar as competências essenciais de seus profissionais. Essas empresas encontraram tal maneira através da EC.

Com média de 2,22 pontos, a "Utilização de novas tecnologias para a disseminação do conhecimento" e o "Aumento das oportunidades de melhoria de competências nas áreas técnicas” fecham as ações de maior importância no favorecimento da efetivação das atividades em EC.

Conforme pesquisa realizada pelo $\mathrm{MDIC} / \mathrm{STI}$ (BRASIL, 2007), também foi observado um alto nível de importância no item "Favorecimento da mudança da
Tabela 2. Ações consideradas de média importância no favorecimento da efetivação da EC.

\begin{tabular}{lc}
\hline \multicolumn{1}{c}{$\begin{array}{c}\text { Atividades que tiveram um favorecimento } \\
\text { intermediário para a implantação da EC }\end{array}$} & Pontos \\
\hline $\begin{array}{l}\text { Preencher as lacunas de cursos não oferecidos pelas IES } \\
\text { Sensibilizar e conscientizar sobre a cidadania corporativa }\end{array}$ & 2,0 \\
$\begin{array}{l}\text { Desenvolver processos estruturados para a socialização do } \\
\text { conhecimento }\end{array}$ & 1,89 \\
$\begin{array}{l}\text { Nivelar o conhecimento técnico, especialmente dos } \\
\text { setores operacionais }\end{array}$ & 1,89 \\
$\begin{array}{l}\text { Criar oportunidades para o surgimento de líderes, a partir } \\
\text { de destaques no desempenho }\end{array}$ & 1,78 \\
$\begin{array}{l}\text { Conscientizar a importância da disponibilidade do } \\
\text { conhecimento }\end{array}$ & 1,67 \\
Fortalecer parcerias com lnstituições de Ensino & 1,67 \\
\hline Fonte: Elaborada a partir dos dados dos questionários e entrevistas.
\end{tabular}

cultura organizacional”. Naquela oportunidade, a ação "Possibilitar o desenvolvimento, entre os colaboradores, de posturas relacionadas com a cidadania corporativa" foi considerada de elevada importância.

As ações que tiveram importância intermediária podem ser visualizadas na Tabela 2. Com média de 2 pontos no grau de importância, aparecem "Preencher as lacunas deixadas pelas Instituições de Ensino" e "Sensibilizar e conscientizar sobre a cidadania corporativa - missão, visão, valores corporativos”.

Cidadania corporativa é a difusão da visão, missão, propósitos, cultura, princípios e tradições de uma organização, de maneira a conseguir identificar uma consistente ligação entre os colaboradores e a empresa, e a conscientização deles aos valores centrais dela (AMARAL, 2001).

De acordo com Fleury e Fleury (2001), a construção da cultura organizacional está ligada ao desenvolvimento da cidadania corporativa e ao conhecimento da estrutura do negócio. A Cidadania Corporativa busca desenvolver valores, crenças, tradições e a cultura organizacional em todos os funcionários da empresa nos diversos níveis hierárquicos, estimulando o orgulho e fortalecendo seu vínculo com a empresa.

Meister (1999) também cita o valor da conscientização da cidadania corporativa, enfatizando que o treinamento formal de funcionários de todos os níveis nos valores, crenças e cultura da organização é uma das características mais marcantes da unidade de EC. No entanto, as empresas deste estudo consideraram que a cidadania corporativa merece importância média.

Logo depois, surgem "Desenvolver processos estruturados para a socialização do conhecimento" e "Nivelar o conhecimento técnico, especialmente dos setores operacionais", com 1,89 pontos e, na sequência, a ação de "Criar oportunidades para o surgimento 
de líderes, a partir de destaque no desempenho das atividades" recebeu 1,78 pontos.

Empatadas em 1,66 pontos, na lista de ações consideradas de média importância para o favorecimento da efetivação da EC, aparecem "Conscientizar a importância da disponibilidade do conhecimento" e "Fortalecer as parcerias com Instituições de Ensino".

$\mathrm{Na}$ ação de fortalecimento de parcerias com instituições de ensino superior tradicionais, Alperstedt (2001) menciona a existência de uma troca benéfica para os dois lados. As unidades de EC são beneficiadas com a validação de créditos para emissão de diplomas para seus colaboradores e ainda conta com a expertise de docentes da instituição tradicional. Por sua vez, as instituições de ensino tradicionais aumentam sua clientela e aumentam o potencial de seus profissionais de observar a atualidade das organizações, produzindo aulas mais próximas da realidade.

Observa-se que as variações entre as atividades destacadas nesse grupo intermediário apresentam diferenças pequenas. Isso comprova que essas atividades não são vistas como as primordiais para as empresas deste estudo multicaso. Porém, também não configuram como as menos importantes. Cabe ressaltar que a diferença entre a menor nota $(1,66)$ e a maior nota desse grupo $(2,0)$, pode sugerir pouca importância estatística. Ainda assim, há uma manifestação de distinção no favorecimento da implementação da EC para algumas atividades.

Finalizando essa etapa, os dirigentes apontaram as ações que pouco influenciaram na efetivação da EC em suas organizações. Observando a Tabela 3, as ações apontadas pelos dirigentes das organizações pesquisadas foram: "Estruturar um sistema de avaliação dos resultados alcançados com investimentos em treinamentos" e "Incentivar ações de inovação de produtos, de serviços e de gestão", as quais receberam 1,56 pontos de média.

Todavia, Eboli (2004) destaca que é imperativo avaliar o treinamento dos colaboradores para a verificação do real benefício para o negócio da empresa. Mas essa avaliação requer um esforço excessivo para a empresa, visto que é desafiador tornar os programas educacionais economicamente viáveis, e isso pode ser o motivo da baixa pontuação dessa ação, de acordo com as empresas do estudo.

Outro princípio da EC relatado por Meister (1999) é justamente "Criar um Sistema de Avaliação dos Resultados e dos Investimentos". No entanto, há o desafio de conseguir a análise dos serviços prestados pela unidade de EC com os resultados obtidos pela empresa. Na maioria das vezes, existe simplesmente um sistema para medir os investimentos de acordo
Tabela 3. Ações consideradas de pouca importância no favorecimento da efetivação da EC.

\begin{tabular}{lc}
\hline Ações com baixo favorecimento na implantação da EC & Pontos \\
\hline $\begin{array}{l}\text { Estruturar um sistema de avaliação dos resultados } \\
\text { alcançados com os investimentos em treinamentos }\end{array}$ & 1,56 \\
$\begin{array}{l}\text { Incentivar ações de inovação de produtos, de processos } \\
\text { e de gestão }\end{array}$ & 1,56 \\
$\begin{array}{l}\text { Melhorar o clima organizacional } \\
\text { Facilitar a integração das equipes, principalmente as de } \\
\text { setores diferentes }\end{array}$ & 1,44 \\
$\begin{array}{l}\text { Apoiar as práticas de gestão de conhecimento existentes } \\
\text { na empresa }\end{array}$ & 1,44 \\
$\begin{array}{l}\text { Criar um ambiente de aprendizagem propício para a } \\
\text { integração de novos colaboradores, devido a estratégias } \\
\text { de fusão }\end{array}$ & 1,22 \\
$\begin{array}{l}\text { Tornar equipes mais flexíveis para eventuais mudanças } \\
\text { estratégicas }\end{array}$ & 1,11 \\
$\begin{array}{l}\text { Melhorar a imagem organizacional, especialmente para } \\
\text { os acionistas }\end{array}$ & 1,0 \\
\hline $\begin{array}{l}\text { Fonte: Elaborada a partir dos dados dos questionários e entrevistas. } \\
\end{array}$
\end{tabular}

com o número horas que os colaboradores passaram em treinamento.

Como visto, as organizações em estudo demonstraram certa contrariedade na ação de estruturar um sistema de avaliação dos resultados alcançados com os investimentos em treinamentos, quando relacionado à literatura. Essas empresas atribuíram notas de pouca importância no favorecimento da implantação da EC para essa atividade, enquanto que a literatura mostra que é fundamental a criação e manutenção de um sistema de avaliação dos resultados.

Com 1,44 pontos na média das notas atribuídas pelas organizações em estudo, aparecem "Melhorar o clima organizacional", "Facilitar a integração de equipes, principalmente as de setores diferentes" e "Apoiar as práticas de gestão do conhecimento existentes na empresa".

De acordo com Freitas (2003), a integração de equipes de trabalho, bem como sistemas para a capacitação e disseminação do conhecimento, mapeamento de processos, aplicações de gerenciamento estatístico de dados são iniciativas para as práticas da gestão do conhecimento.

Por outro lado, são compreensíveis as ações de melhoramento do clima organizacional e integração das equipes estarem no mesmo patamar de importância, uma vez que as equipes, ou seja, pessoas estarem diretamente ligadas ao clima da organização.

As ações que receberam menor nota, indicando aquelas que tiveram pouca influência na efetivação da EC nas organizações foram "Criar um ambiente de aprendizagem propício para a integração de novos colaboradores, devido a estratégias de fusão" com 1,22 pontos, "Tornar equipes mais flexíveis para eventuais mudanças estratégicas" com 1,11 pontos 
e "Melhorar a imagem organizacional, especialmente para os acionistas" com apenas 1 ponto.

Diferentemente do que aconteceu na pesquisa realizada pelo Ministério do Desenvolvimento da Indústria e Comércio Exterior (2007) , quando a ação "Melhorar a imagem organizacional como marketing da empresa" foi apontada como de média importância, essa prática ficou em último lugar quanto ao nível de importância para as organizações deste estudo.

Como se pode notar, são vários os fatores que favorecem a criação de uma unidade de EC nas organizações, mas é de fundamental importância a participação dos líderes no processo de aprendizagem contínua. Também há um entendimento quanto ao favorecimento da mudança da cultura organizacional, como um dos principais fatores da adoção dessa prática da gestão do conhecimento.

\section{Estágio de desenvolvimento da EC}

A próxima questão procurou obter dados sobre 0 estágio de desenvolvimento da EC nas organizações deste estudo. A resposta poderia ser escolhida a partir de 6 (seis) níveis diferentes, e apenas uma delas deveria ser suficiente para determinar o seu real nível.

Os coordenadores podiam optar por:

- Fase de idealização, com planejamento para start-up em futuro próximo;

- Iniciação, com atividades em fase de estruturação;

- Atividades em andamento, porém com atendimento aos níveis operacionais;

- Atividades em andamento, voltadas aos níveis operacionais quanto aos níveis de gerência média (nível tático);

- Atividades em andamento, consolidadas, com atendimento a toda a organização nos níveis operacional, tático e estratégico;

- Atividades em andamento, consolidadas, voltadas ao atendimento de toda a organização nos níveis operacional, tático e estratégico, além de desenvolver atividades com atendimento aos fornecedores, clientes e comunidade.

Novamente houve uma resposta que atendeu ao nível de desenvolvimento da maioria. Nessa questão, 55,55\% das organizações, de acordo com os gestores responsáveis pela unidade de educação corporativa, encontram-se no mais elevado nível de desenvolvimento das atividades de EC, abrangendo todos os stakeholders, e 44,44\% responderam que se encontram com atividades em andamento, consolidadas, com atendimento a toda a organização nos níveis operacional, tático e estratégico, faltando, entretanto, $\mathrm{o}$ atendimento aos fornecedores, clientes e comunidade, conforme Tabela 4.

Como Eboli (2004) relata sobre um dos conceitos da EC, o desenvolvimento das competências internas e externas deve atender a família, fornecedores, clientes, parceiros comerciais e comunidade.

Dessa forma, dessa amostra de organizações brasileiras que têm suas estratégias alinhadas ao processo de EC, a maioria está de acordo com ensinamentos encontrados na literatura.

\section{Atividades em EC desenvolvidas}

Na sequência, buscou-se apresentar as atividades em EC que já estão em andamento nas organizações. Novamente foi requisitado aos respondentes que atribuíssem nota " 3 " para as ações mais importantes desenvolvidas na organização, "2" para as de importância intermediária, "1" para as de menor importância e "0" para as ações não desenvolvidas.

A opção aberta de resposta, sob o nome de “outra”, também apareceu nessa questão, e o responsável pela EC pôde mencionar atividades que não estavam relacionadas no questionário. Mais uma vez nenhum respondente utilizou dessa opção. Assim, os dados foram baseados nas alternativas previstas no questionário.

Ações como as "Atividades no desenvolvimento das competências profissionais", com 2,56 pontos; as "Atividades direcionadas à melhoria da performance funcional", com 2,44 pontos; as "Ações voltadas à integração de novos colaboradores" e a "Criação de parcerias com instituições de ensino", com 2,33 pontos; "Programas desenvolvidos para elevar o capital intelectual da empresa" e "Promoção da melhoria contínua dos processos internos", com 2,22 pontos receberam as maiores pontuações, conforme Tabela 5.

Uma unidade de EC tem o desenvolvimento das competências profissionais, técnicas e gerenciais

Tabela 4. Estágios de desenvolvimento das atividades de EC.

\begin{tabular}{l} 
Estágio das atividades em educação corporativa \\
\hline $\begin{array}{l}\text { Atividades em andamento, consolidadas, voltadas ao atendimento de toda a organização nos níveis operacional, tático e } \\
\text { estratégico, além de desenvolver atividades com atendimento aos fornecedores, clientes e comunidade. }\end{array}$ \\
Atividades em andamento, consolidadas, com atendimento a toda a organização nos níveis operacional, tático e estratégico. \\
\hline Fonte: questionário dos autores (2008).
\end{tabular}


Tabela 5. Atividades em EC com maior importância desenvolvidas pelas organizações.

\begin{tabular}{lc}
\hline $\begin{array}{l}\text { Atividades em EC com maior importância desenvolvidas } \\
\text { pelas organizações em estudo }\end{array}$ & Pontos \\
\hline $\begin{array}{l}\text { Atividades no desenvolvimento das competências } \\
\text { profissionais }\end{array}$ & 2,56 \\
$\begin{array}{l}\text { Atividades direcionadas a melhoria da performance } \\
\text { funcional }\end{array}$ & 2,44 \\
$\begin{array}{l}\text { Ações voltadas à integração de novos colaboradores } \\
\text { Criação de parcerias com instituições de ensino }\end{array}$ & 2,33 \\
$\begin{array}{l}\text { Programas desenvolvidos para elevar o capital intelectual } \\
\text { da empresa }\end{array}$ & 2,33 \\
Promoção da melhoria contínua dos processos internos & 2,22 \\
\hline Fonte: elaborada a partir dos dados dos questionários e entrevistas.
\end{tabular}

consideradas essenciais para o alinhamento das estratégias da organização como seu principal objetivo, de acordo com Nunes (2005).

Meister (1999) ainda aponta para as 7 competências essenciais para o ambiente de negócios: Aprender a aprender, pois espera-se dos colaboradores uma postura voltada ao aprendizado; Comunicação e colaboração, por melhorar o relacionamento com clientes e fornecedores e até mesmo em trabalhos em equipe; Raciocínio criativo e resolução de problemas, por se tratar de competências exigidas aos colaboradores em geral; Conhecimento de negócios globais, para estar atento às oscilações da conjuntura interna e internacional; Conhecimento tecnológico, a fim de ampliar o alcance na obtenção de melhores práticas e observação dos concorrentes; Desenvolvimento de liderança, uma vez que todos são responsáveis pelo desempenho da organização; e Autogerenciamento da carreira, por permitir autonomia de traçar seu próprio plano de carreira e buscar novas qualificações para sua evolução profissional.

Constata-se que o desenvolvimento das competências profissionais é uma preocupação das organizações participantes deste estudo e está em conformidade com os ensinamentos encontrados na literatura.

Observou-se que "Atividades que busquem o aumento da capacidade intelectual dos colaboradores" e "Programas em educação com o intuito de disseminar a cultura organizacional" com 2,11 pontos; "Apoio à formação educacional dos colaboradores”, "Atividades que fortaleçam a integração e o trabalho em equipe, tornando-as mais flexíveis e ágeis para eventuais mudanças estratégicas" e "Suporte no desenvolvimento de conhecimentos, habilidades e atitudes" obtiveram nota igual a 2,0 pontos e foram as ações que tiveram notas de importância intermediárias, conforme Tabela 6.
Tabela 6. Atividades em EC com média importância desenvolvidas pelas organizações.

\begin{tabular}{lc}
\hline \multicolumn{1}{c}{$\begin{array}{c}\text { Atividades em EC com média importância } \\
\text { desenvolvidas pelas organizações em estudo }\end{array}$} & Pontos \\
\hline $\begin{array}{l}\text { Atividades que busquem o aumento da capacidade } \\
\text { intelectual dos colaboradores }\end{array}$ & 2,11 \\
$\begin{array}{l}\text { Programas em educação com o intuito de disseminar a } \\
\text { cultura organizacional }\end{array}$ & 2,11 \\
$\begin{array}{l}\text { Apoio à formação educacional dos colaboradores } \\
\text { Atividades que fortaleçam a integração e o trabalho em }\end{array}$ & 2,0 \\
$\begin{array}{l}\text { equipe, tornando-as mais flexíveis e ágeis para eventuais } \\
\text { mudanças estratégicas }\end{array}$ & 2,0 \\
$\begin{array}{l}\text { Suporte no desenvolvimento de conhecimentos, habilidades } \\
\text { e atitudes }\end{array}$ & 2,0 \\
\hline $\begin{array}{l}\text { Fonte: elaborada a partir dos dados dos questionários e entrevistas. } \\
\end{array}$
\end{tabular}

Eboli (2004) ressalta que a EC no Brasil está deixando de ser uma proposta e está se transformando em uma importante arma para empresas que querem se tornar mais competitivas. Essas empresas apoiam um crescente incentivo à sua capacidade intelectual, após terem observado a real importância de investimento no ser humano, como um dos seus principais capitais.

Isso se comprova com essa pesquisa, pois as organizações respondentes atribuíram 2,11 pontos de média, mostrando-se favoráveis ao estímulo do aumento de seu capital intelectual.

Com relação às atividades em EC com pouca importância desenvolvidas pelas organizações em estudo, o "Apoio para a realização de programas sociais e ambientais" e "Programas voltados para o alinhamento entre as competências individuais e competências essenciais da empresa" aparecem ambas com 1,78 pontos.

A ação "Cursos voltados aos fornecedores, clientes externos e comunidade" indicou média de 1,44 pontos. Já as ações "Capacitações visando o desenvolvimento das comunidades" e "Promoção da inclusão digital e social da comunidade" ficaram com as menores notas, 1,11 pontos.

Como descrito pelos dirigentes da EC das organizações em estudo (Tabela 7), a atividade da promoção da inclusão digital e social da comunidade ainda não foi realizada ou está sendo realizada com pouca ênfase, devido ao fato da atividade não fazer parte das estratégias das empresas para o momento.

Apesar do tema "responsabilidade social" estar em alta entre as organizações, esse grupo de empresas nacionais tem se preocupado com suas necessidades. 0 alinhamento estratégico foi colocado em primeiro plano e o trabalho de desenvolvimento da comunidade, através da inclusão digital e social, fato que poderia prover uma imagem positiva para o grupo, ficará para ações futuras. 
Tabela 7. Atividades em EC com pouca importância desenvolvidas pelas organizações.

\begin{tabular}{lc}
\hline \multicolumn{1}{c}{$\begin{array}{c}\text { Atividades em EC com média importância } \\
\text { desenvolvidas pelas organizações em estudo }\end{array}$} & Pontos \\
\hline $\begin{array}{l}\text { Apoio para a realização de programas sociais e ambientais } \\
\text { Programas voltados para o alinhamento entre as }\end{array}$ & 1,78 \\
$\begin{array}{l}\text { competências individuais e competências essenciais da } \\
\text { empresa }\end{array}$ & 1,78 \\
$\begin{array}{l}\text { Cursos voltados aos fornecedores, clientes externos e } \\
\text { comunidade }\end{array}$ & 1,44 \\
$\begin{array}{l}\text { Promoção da inclusão digital e social da comunidade } \\
\text { Capacitações visando o desenvolvimento das comunidades }\end{array}$ & 1,11 \\
\hline Fonte: elaborada a partir dos dados dos questionários e entrevistas. &
\end{tabular}

\section{Resultados percebidos após a EC}

Na sequência, o questionário indagou sobre os resultados alcançados após a implantação das atividades de EC nas organizações. Todas as 9 (nove) empresas responderam a esta pergunta, atribuindo "3" para o mais importante e "0" para o menos importante ou resultado não notado (Tabela 8). Nota-se que havia uma opção aberta de resposta, com o título de "outra", na qual o coordenador da unidade de EC poderia descrever atividades não previstas no questionário.

Apenas 2 (duas) organizações mencionaram itens diferentes dos relacionados: Melhor geração e disseminação do conhecimento na empresa; Envolvimento dos líderes no processo de aprendizagem; e Criação de uma Unidade de Negócios.

Assim, é possivel interpretar esta questão em três categorias a partir da tabulação dos seus resultados: significativamente, parcialmente, e pouco notados.

- Significativamente notados - Melhoria do desempenho dos colaboradores do nível operacional; Elevação da competência individual; Melhoria do desempenho dos colaboradores do nível tático; Aumento da competitividade da organização; Aumento do capital intelectual da organização; Conscientização da cidadania corporativa (missão, visão, valores organizacionais); Facilitação do alcance das metas; e Elevação das competências essenciais da organização;

- Parcialmente notados - Aumento do grau de satisfação dos colaboradores do nível tático; Melhoria do desempenho dos colaboradores do nível estratégico; Aumento do grau de satisfação dos colaboradores do nível estratégico; Aumento do grau de satisfação dos colaboradores do nível operacional; Favorecimento das parcerias com instituições de ensino; Melhoria da imagem institucional perante os colaboradores externos; Melhoria da imagem institucional perante os colaboradores internos; Aumento da flexibilidade das equipes em função de mudanças estratégicas; Nivelamento do conhecimento nos diversos setores da empresa; Facilitação dos processos de inovação;
Tabela 8. Resultados alcançados após a implantação do processo de EC.

\begin{tabular}{|c|c|}
\hline Resultados alcançados & Média \\
\hline $\begin{array}{l}\text { Melhoria do desempenho dos colaboradores do nível } \\
\text { operacional } \\
\text { Elevação da competência individual }\end{array}$ & 2,78 \\
\hline $\begin{array}{l}\text { Melhoria do desempenho dos colaboradores do nível tático } \\
\text { Aumento da competitividade da organização }\end{array}$ & 2,67 \\
\hline $\begin{array}{l}\text { Aumento do capital intelectual da organização } \\
\text { Conscientização da cidadania corporativa (missão, visão, } \\
\text { valores organizacionais) } \\
\text { Facilitação do alcance das metas }\end{array}$ & 2,56 \\
\hline Elevação das competências essenciais da organização & 2,44 \\
\hline $\begin{array}{l}\text { Aumento do grau de satisfação dos colaboradores do } \\
\text { nível tático } \\
\text { Melhoria do desempenho dos colaboradores do nível } \\
\text { estratégico } \\
\text { Aumento do grau de satisfação dos colaboradores do } \\
\text { nível estratégico }\end{array}$ & 2,33 \\
\hline $\begin{array}{l}\text { Aumento do grau de satisfação dos colaboradores do } \\
\text { nível operacional } \\
\text { Favorecimento das parcerias com instituições de ensino }\end{array}$ & 2,22 \\
\hline $\begin{array}{l}\text { Melhoria da imagem institucional perante os colaboradores } \\
\text { externos } \\
\text { Melhoria da imagem institucional perante os colaboradores } \\
\text { internos }\end{array}$ & 2,11 \\
\hline $\begin{array}{l}\text { Aumento da flexibilidade das equipes em função de } \\
\text { mudanças estratégicas } \\
\text { Nivelamento do conhecimento nos diversos setores da } \\
\text { empresa } \\
\text { Facilitação dos processos de inovação } \\
\text { Melhoria da imagem institucional perante a comunidade }\end{array}$ & 1,89 \\
\hline Favorecimento da integração das equipes & 1,78 \\
\hline $\begin{array}{l}\text { Diminuição da rotatividade dos colaboradores } \\
\text { Aumento de programas sociais e ambientais realizados }\end{array}$ & 1,67 \\
\hline Diminuição do custo de recrutamento e seleção & 1,44 \\
\hline $\begin{array}{l}\text { Melhor geração e disseminação do conhecimento na } \\
\text { empresa } \\
\text { Envolvimento dos líderes no processo de aprendizagem } \\
\text { Criação de uma unidade de negócios }\end{array}$ & 0,33 \\
\hline
\end{tabular}

Fonte: questionário dos autores (2008).

Melhoria da imagem institucional perante a comunidade;

- Pouco notados - Favorecimento da integração das equipes; Diminuição da rotatividade dos colaboradores; Aumento de programas sociais e ambientais realizados; Diminuição do custo de recrutamento e seleção; Melhor geração e disseminação do conhecimento na empresa; Envolvimento dos líderes no processo de aprendizagem; Criação de uma Unidade de Negócios.

Deve-se salientar que as últimas atividades apresentadas como resultados alcançados depois da implantação da EC foram respostas abertas e lembradas por apenas duas organizações. Nisso se baseia o fato da baixa pontuação apontada na Tabela 8, ao contrário de se imaginar serem de pouca importância essas atividades. 
Apesar dos ensinamentos de Meister (1999), que apresentam as atividades em EC como de maior amplitude e a observância do macro, os melhores resultados apresentados pelas organizações em estudo, indicam o individual, e no nível operacional.

Com relação à criação de uma unidade de negócios, Freitas (2003) comenta sobre um fator que tem motivado as organizações a criar suas unidades de EC: a transformação do Departamento de RH, antes um centro de custos, em um centro de lucros. Essas empresas podem distribuir seus produtos, como material didático, serviços, consultorias, aulas para o mercado. Os colaboradores, fornecedores e clientes passam a gerar receitas através das taxas que custeiam as despesas de operacionalidade.

Meister (1998a) comunga do mesmo pensamento, afirmando que a arrecadação de recursos por meio do fornecimento de educação é uma rotina em diversas universidades corporativas. É comum que essas empresas organizadas por unidades de negócio cobrem dos departamentos que demandaram seus serviços de ensino-aprendizagem, como uma maneira de contrabalançar seus custos. A autora ainda ressalta que a estratégia de obtenção de recursos através da remuneração por serviços, transforma-se e aprimora-se na medida em que a universidade corporativa vai aperfeiçoando.

Eboli (2004) também comenta sobre a sustentabilidade, quando declara a importância de ser um centro gerador de resultados para a empresa, buscando sempre agregar valor ao negócio, como apresentado anteriormente no referencial teórico deste trabalho.

Apesar de apenas uma organização mencionar o item criação de uma unidade de negócios, a literatura indica como uma prática normal para as unidades de EC mais evoluídas. lsso leva a supor que as empresas nacionais em estudo, que adotam o processo de $\mathrm{EC}$, ainda estão em fases pouco amadurecidas de desenvolvimento de suas atividades.

\section{Considerações finais}

Este capítulo apresenta as conclusões encontradas após a análise dos dados e dos conteúdos coletados na pesquisa. Discorre acerca das etapas de implementação do processo de EC nas organizações em estudo, das ações e motivos que favoreceram as atividades de EC, além do estágio de desenvolvimento dessas atividades, e os resultados percebidos após a implementação. Faz também menção das limitações deste estudo.

Com relação ao objetivo geral deste trabalho, demonstrar o estágio de desenvolvimento da EC, a maioria das empresas respondentes indicou atividades consolidadas, voltadas à capacitação da organização inteira nos níveis estratégico, tático e operacional, notando que quase metade desses fornece atividades aos seus clientes, fornecedores, e à comunidade em geral.

Referente à comunidade, foi observado que as organizações que indicaram atividades voltadas a ela estão agindo de maneira retraída, justificando que faz parte de seus planos futuros, porém não é estratégico para o momento.

Quanto ao objetivo de "avaliar as etapas de implementação do processo de EC nas organizações brasileiras", pode-se concluir que a maioria das empresas deste estudo indicou que a implementação foi realizada após decisão dos dirigentes como a etapa inicial, ou seja, o primeiro passo partiu da alta cúpula.

Os dirigentes das organizações tomaram a decisão da criação da unidade e desenvolveram, na sua maioria, um projeto inicial de implantação.

A próxima etapa apontada pelas organizações respondentes foi a realização de um diagnóstico das competências críticas da empresa. Esse diagnóstico servirá para alinhar as competências essenciais do indivíduo e as competências necessárias para o seu cargo, tornando-as compatíveis.

A etapa seguinte foi a análise da avaliação dos colaboradores nos treinamentos anteriormente desenvolvidos. Dessa forma, é possível determinar os pontos fortes do modelo de ensino-aprendizagem utilizado e também as oportunidades de melhoria.

Então, as organizações brasileiras participantes desta pesquisa partiram para a etapa do desenvolvimento de um novo projeto para a implementação da EC. Tal projeto determina os conteúdos e seus responsáveis, modelo e forma de abordagem, público-alvo e parcerias com outras instituições.

Observou-se que a sequência "Decisão dos Dirigentes" na criação de um "Projeto Inicial de Implantação", seguido pelo "Diagnóstico das Competências" essenciais para a organização e "Avaliação dos Treinamentos" anteriormente desenvolvidos, levaram para a última etapa que é um "Novo Projeto de Implementação" da EC.

Essa é a sequência de etapas que melhor interpreta as respostas dos dirigentes das unidades de EC em estudo, ou seja, a maioria das organizações desse grupo apontou para essa sucessão de etapas.

No que diz respeito aos demais impactos da EC, foram mapeadas as atividades em EC desenvolvidas nesta amostra de organizações nacionais. As atividades que receberam notas mais significativas quanto ao seu grau de importância foram aquelas em prol do desenvolvimento das competências profissionais e aquelas direcionadas à melhoria da performance funcional. 
Relativamente à identificação das ações e motivos que favoreceram a criação da unidade de EC sobressaiu o "Envolvimento de líderes e gestores da empresa com o processo de aprendizagem contínua" e o "Favorecimento da mudança da cultura organizacional".

Em consonância com os princípios da EC, outra ação mencionada como favorável à criação da unidade foi o apoio ao cumprimento dos objetivos estratégicos da empresa, além da criação de um ambiente organizacional propício ao aprendizado contínuo.

0 último aspecto analisado neste trabalho procurou avaliar os resultados observados após a implantação da EC nas organizações. Os resultados percebidos como de maior relevância foram a "Elevação da competência individual", o "Aumento do capital intelectual da organização".

$\mathrm{Na}$ busca pela apresentação das etapas de implementação do processo de EC em empresas brasileiras, este estudo conclui que para a criação da unidade deve-se levar em consideração a singularidade de cada empresa, com suas características e especificidades. As etapas para a implementação da EC deverá ser compatível com a cultura, os valores, o modelo de gestão da organização que pretende adotá-la.

É fundamental que haja flexibilidade, pois se constatou que não há uma receita a ser seguida. Nem foi esse o objeto deste estudo, encontrar um modelo de implantação da EC. Encontrou-se, porém, uma sequência de etapas, mesmo havendo algumas divergências de acordo com as diferentes organizações. No entanto, que o ato da decisão de criar uma unidade de EC deva partir dos dirigentes como o primeiro passo, pareceu ser o mais assertivo, em conformidade com a literatura sobre o tema.

A opinião dos responsáveis pela EC pode ser considerada como uma das limitações deste estudo, o qual utiliza, nas suas conclusões, ponto de vista que privilegia a ótica dos dirigentes dessas unidades. Outra limitação se deve ao fato de que os resultados aqui apresentados demonstram a realidade desse grupo de grandes organizações brasileiras, podendo apresentar divergências em outros grupos.

Com o estudo, pode-se observar que a empresa que adota a Educação Corporativa enfatiza as competências dos colaboradores. Assim, melhora a satisfação dos funcionários, pois esta nova cultura organizacional os beneficia de maneira mais abrangente do que simplesmente aprender habilidades específicas, ou melhorar o desempenho nas tarefas.

A EC focaliza nas competências do empregado e alcança sua missão de desenvolver programas educacionais adequadamente conectados aos objetivos do negócio e estratégia organizacional.

As principais vantagens da EC apontadas pelas empresas respondentes deste estudo multicaso são a melhoria do desempenho dos colaboradores; a elevação da competência individual; e o aumento da competitividade da organização.

Observou-se que as organizações pesquisadas têm atuado em prol da educação. Essas acreditam que, quanto maior o acesso à atualização do conhecimento e das competências de seus colaboradores, maior as chances de obter vantagem competitiva.

Finalmente, a implementação da unidade de EC deve levar em consideração as particularidades de cada empresa, pois inexiste uma fórmula capaz de atender a todas as organizações.

\section{Referências}

ALLEN, M. Introduction: what is a corporate university, and why should an organization have one? In: ALLEN, M. (Org.). The corporate university handbook. New York: Amacom, 2002.

ALPERSTEDT, C. As Universidades Corporativas no contexto do ensino superior. Tese (Doutorado em Administração)Universidade de São Paulo, São Paulo, 2001.

BLASS, E. The rise and rise of the corporate university. Journal of European Industrial Training, v. 29, n. 1, p. 58-74, 2005. Disponivel em: <http://www.emeraldinsight.com/ Insight/viewPDF.jsp?Filename $=$ html/Output/Published/ EmeraldFullTextArticle/Pdf/0030290104.pdf>. Acesso em: out. 2007.

BOHLANDER, G.; SNELL, S.; SHERMAN, A. Administração de recursos humanos. São Paulo: Pioneira Thomson Learning, 2003.

BRASIL. Ministério do Desenvolvimento, Indústria e Comércio Exterior - MDIC. Disponível em: http://www. desenvolvimento.gov.br>. Acesso em: feb. 2007.

EBOLl, M. Educação corporativa no Brasil: mitos e verdades. São Paulo: Gente 2004.

FERNANDES, G. H. Análise comparativa entre a Universidade Corporativa Caixa e o Modelo de Meister. 2005. $123 \mathrm{f}$. Dissertação (Mestrado em Engenharia de Produção)Universidade Federal de Santa Catarina, Florianópolis, 2005.

FLEURY, A.; FLEURY, M. T. L. Estratégias empresariais e formação de competências. 2. ed. S. Paulo: Atlas, 2001.

FREITAS, M. C. D. Educação corporativa: um método de apoio à decisão para implantação nas organizações empresariais. 2003. 189 f. Tese (Doutorado em Engenharia de Produção)-Universidade Federal de Santa Catarina, Florianópolis, 2003.

GlL, A. C. Métodos e Técnicas de Pesquisa Social. 5. ed. São Paulo: Ed. Atlas, 1999.

MEISTER, J. C. Corporate Universities: lessons in building a world-class work force. McGraw-Hill Trade, 1998a. 
MEISTER, J. C. Extending the short shelf life of knowledge. Training and Development, McGraw-Hill Trade, 1998b.

MEISTER, J. C. Educação corporativa: a gestão do capital intelectual através das universidades corporativas. São Paulo: Makron Books, 1999.

MEISTER, J. C. Corporate Universities: What works and what doesn't. 2006. Disponivel em: <http:// www.clomedia.com/content/templates/clo_article. asp? articleid=1454\&zoneid=58>. Acesso em: maio 2007.

NUNES, 1. H. Requisitos para determinar a validade de transformação de um centro de treinamento de uma empresa do setor elétrico em Universidade Corporativa. 2005. 111 f. Dissertação (Mestrado em Engenharia de Produção)-Universidade Federal de Santa Catarina, Florianópolis, 2005.
SEBRAE. Disponível em: <http://www.sebrae.com.br>. Acesso em: abr. 2007.

TARAPANOFF, K. Panorama da Educação Corporativa no Contexto Internacional. Brasília: Editora UnB, 2004.

VARGAS, M. R. M.; LIMA, S. M. V. Barreiras à Implantação de Programas de Educação e Treinamento a Distância. In: CONGRESSO INTERNACIONAL DE EDUCAÇÃO A DISTÂNCIA, 11., 2004, Salvador. Anais... Salvador: CIED, 2004.

VIANNA, M. A. Estratégia e Humanismo. Instituto MVC, 2004. Disponível em: <http://www.institutomvc.com. br/>. Acesso em: 15 nov. 2007.

YIN, R. K. Estudo de Caso: Planejamentos e Métodos. 2. ed. Porto Alegre: Bookman, 2001.

\title{
Corporate education implementation stages and their impacts on Brazilian companies - a multi-case study
}

\begin{abstract}
This study presents the corporate education (CE) in Brazilian organizations as a means of continuous learning, despite the fact that this practice is still under development in the country. The purpose of this research was to analyze the implementation stages of the CE process through a multi-case study. It was possible to observe that the CE unit implementationshould consider the singularities of each company, with its characteristics and specificities. It is possible to conclude that most enterprises in this study indicated that the implementation was carried out after the executives' decision as the first phase. Although there is no formula capable of meeting the specifications of all organizations, there was a logical sequence for the structuring and implementation of the unit.
\end{abstract}

\section{Keywords}

Corporate education. Continuous learning. Brazilian organizations. 